\title{
Article \\ The Hollowing Process of Rural Communities in China: Considering the Regional Characteristic
}

\author{
Ying Liu *(D), Liqiong Shu and Li Peng (1) \\ The College of Geography and Resources, Sichuan Normal University, Chengdu 610066, China; \\ 20191103007@stu.sicnu.edu.cn (L.S.); pengli@imde.ac.cn (L.P.) \\ * Correspondence: liuying@imde.ac.cn; Tel.: +86-18-123-385-723
}

Citation: Liu, Y.; Shu, L.; Peng, L.

The Hollowing Process of Rural Communities in China: Considering the Regional Characteristic. Land 2021, 10, 911. https://doi.org/ 10.3390/land10090911

Academic Editor: Hossein Azadi

Received: 20 July 2021

Accepted: 18 August 2021

Published: 28 August 2021

Publisher's Note: MDPI stays neutral with regard to jurisdictional claims in published maps and institutional affiliations.

Copyright: (C) 2021 by the authors. Licensee MDPI, Basel, Switzerland. This article is an open access article distributed under the terms and conditions of the Creative Commons Attribution (CC BY) license (https:// creativecommons.org/licenses/by/ $4.0 /)$.

\begin{abstract}
This study examined the hollowing process of rural communities, which is caused by migration, and explored its influence factors based on Hierarchical Linear Model (HLM) analysis in an attempt to explore effect of regional characteristic. To capture the essence of rural hollowing, a logical framework was constructed. The rural hollowing was then evaluated based on an index system. Based on the assessment, HLM analysis was conducted to explore the influence factors at the household and community levels. The results demonstrated significant differences of rural hollowing among villages. In addition, the hollowing was not only affected by household-level variables but also by community-level variables. Further, for rural hollowing, the household-level variable was endogenous drive, while the community-level variables were exogenous drive. Among all the endogenous influence factors, population quality was the most important, and thus the loss of highly educated talents will aggravate the trend of rural hollowing and hinder the sustainable development of the countryside. Furthermore, in addition to promoting economic development and its diversification to alleviate rural hollowing, improving the quality of the population is more important to the sustainable development of the countryside in China.
\end{abstract}

Keywords: rural hollowing; population decline; aging population; migration; HLM

\section{Introduction}

Population hollowing in rural settlements is one of the most significant social issues for many countries. Particularly in recent years, several researchers have identified rural communities as "pioneer" areas given their prior experiences with social changes caused by population hollowing [1]. Different disciplines define rural population hollowing from different perspectives, although two are the most common: sociological and geographical. From the sociological perspective, hollowing refers to the phenomenon of low social and economic development: changes in the organizational structure of rural society and social and cultural life due to the decrease of population, especially young and middle-aged inhabitants; the lack of popularity and vitality in rural society; and the low level of social and economic development [2]. This viewpoint emphasizes the fundamental changes in the structure of rural society caused by population migration. The geographical perspective focuses on the change of spatial form, which emphasizes the spatial form of extensive rural land use and the expansion of inner space caused by population migration [3-5].

Researchers generally believe that population hollowing is the decline of community autonomy and organizational activities caused by population decline and aging [1]. It is a multistage process, including the stage of increasing vulnerability, the stage in which a population changes from growth or stability to instability or decline, and the stage of population migration, which leads to decreasing adaptability of the remaining residents [6]. Identifying the process of population hollowing can help decision makers formulate strategies for rural sustainable development. Different scholars have proposed the hollowing classification framework from different perspectives. Robert A. McLeman depicted the 
process of population hollowing in terms of population size changes, vulnerability, and driving force, primarily emphasizing the changes of population and environmental factors in the process of population hollowing [7]. Kasamatsu, Odagiri, and Sakuno suggested classifying the degree of rural population hollowing using the relationship between population size and community function. Kasamatsu et al. emphasized the degradation of community functions caused by population changes in the process of population hollowing from the perspective of rural residents' living standards.

Due to further understanding of the connotations of population hollowing, exploring the causes of population hollowing has attracted attention that is more academic. At first, the migration of the rural population, especially young people, was considered to be the most important reason for population hollowing. With the deepening understanding of the human-environment relationship, scholars have proposed that population migration and rural structural changes are potentially influenced by various environmental factors [8-10], such as environmental changes, natural disasters, and other events [7,11-13]. In addition, urbanization and industrialization are also considered to be the main factors affecting population hollowing. By 2030, the global urbanization rate is projected to reach about $60 \%$, with most of the growth coming from developing countries, leading to an increasing amount rural out-migration in developing countries. Contrary to this, counter-urbanization, a new type of inward migration to rural areas that first appeared in the 1960s-1970s, is expected to be a means for the possible recovery of rural populations $[14,15]$.

Based on the pattern found in developed countries, when the urbanization rate is close to $60 \%$, rural population hollowing will be intensified [16]. Japan and South Korea can be taken as examples. Since the 1960s and 1970s, a large amount of the rural population has been drained, and the problem of population hollowing in rural areas has become increasingly serious. In China, the acceleration of the national urbanization process will directly promote the accelerated transfer of the rural population, and population hollowing of rural areas will continue to increase over an extended period. Sampling data from administrative villages in China's third national agricultural census of 2016 revealed that the number of administrative villages with a net outflow of population accounted for $79.01 \%$ of the total, among which the proportion of so-called "hollow villages," that is, those with a hollowing rate $\geq 5 \%$, was $57.50 \%$, while the overall hollowing rate was $23.98 \%$. More importantly, rural population hollowing is negatively correlated with economic development. The proportion of hollow villages in the eastern provinces of China is lower, while the proportions in the central and western regions are generally higher [17].

However, since research on the rural population in China has mainly focused on land use change, its perspective has been the vacancies of rural homesteads $[5,18,19]$, a phenomenon whose formation mechanism and expression differ from rural population hollowing. Research exploring the rural population hollowing of China from a comprehensive perspective has been relatively insufficient. More importantly, scant attention has been paid to the relationship between population hollowing and rural sustainability. A complete understanding of the rural population hollowing in China will help China implement rural revitalization and new urbanization strategies for different types of villages. Therefore, the objective of this study was to establish a comprehensive framework, which fully considers the rural structure and functional changes caused by population migration, in order to evaluate the rural population hollowing in China, and to explore the influence factors from both macro- and microperspectives, in an attempt to investigate the relationship between rural hollowing and rural sustainability. To achieve these goals, this study selected Sichuan Province, which is located in western China and has the largest net outflow of rural population, to evaluate rural population hollowing and to explore its driving mechanisms using HLM analysis, considering both household-level and community-level variables, with the hope of revealing the key to the sustainable development of rural areas in China. 


\section{Materials and Methods}

\subsection{Data Sources}

The statistics used in this study originated from the survey data of the field investigation that took place during January 2020 in Sichuan Province, China. During the winter vacation period of college students, we conducted a questionnaire survey. The hometown distribution of the students was random, so the selected sample points were random. Ultimately, a total of 31 college students were recruited, involving 31 villages. This survey was composed of two sections: (1) a questionnaire-based survey to households and (2) an interview survey with the chairperson of each village. The household survey accounted for $10 \%$ of the total number of households for each village. A total of 551 household questionnaires and 31 village questionnaires were eventually received. After eliminating the unqualified questionnaires, the final effective questionnaires included 451 household questionnaires and 21 village questionnaires from the 31 villages. The details of the sample villages are shown in Figure 1 and listed in Table 1.

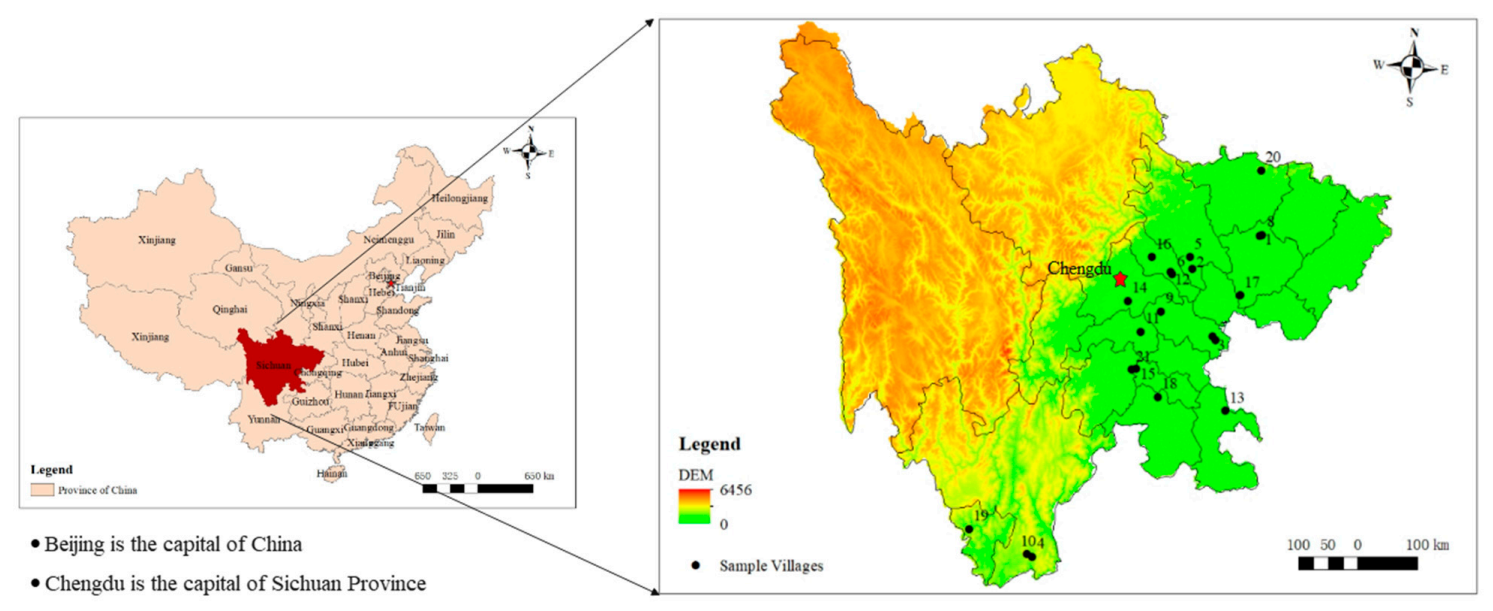

Figure 1. Location map of sample villages.

Table 1. The detail information of the sample villages.

\begin{tabular}{|c|c|c|c|c|c|c|}
\hline Name & ID & $\begin{array}{c}\text { Total } \\
\text { Households }\end{array}$ & $\begin{array}{c}\text { Total } \\
\text { Population }\end{array}$ & $\begin{array}{c}\text { Total Area of } \\
\text { Agricultural } \\
\text { Land (ha) }\end{array}$ & $\begin{array}{l}\text { Per Capita Net } \\
\text { Income of } \\
\text { Farmers (CNY) }\end{array}$ & $\begin{array}{c}\text { Number of } \\
\text { Households Living } \\
\text { Away from Home }\end{array}$ \\
\hline Biluo & 1 & 555 & 2265 & 514.89 & $11,058.5$ & 83 \\
\hline Changxing & 2 & 238 & 937 & 381.9 & 8635.7 & 45 \\
\hline Qinggang & 3 & 161 & 715 & 205.355 & 8675 & 26 \\
\hline Changyu & 4 & 296 & 1255 & 289.44 & 15,600 & 90 \\
\hline Anle & 5 & 182 & 782 & 224.45 & 14,352 & 7 \\
\hline Xinfa & 6 & 536 & 2065 & 323.007 & 6322 & 20 \\
\hline Sazheyi & 7 & 358 & 1468 & 125.156 & 9200 & 105 \\
\hline Nanshan & 8 & 348 & 1628 & 144.72 & 7125 & 75 \\
\hline Guancun & 9 & 432 & 1864 & 215.137 & 13217 & 15 \\
\hline Dishuiyan & 10 & 286 & 1466 & 168.639 & 8722.5 & 16 \\
\hline Wangiiafen & 11 & 232 & 976 & 272.355 & 6811 & 13 \\
\hline Putao & 12 & 297 & 1410 & 101.103 & 9310 & 6 \\
\hline Lugao & 13 & 1080 & 3350 & 113.9 & 4500 & 25 \\
\hline Wangjiachang & 14 & 923 & 2556 & 14.07 & 20,000 & 100 \\
\hline Yingchun & 15 & 352 & 1363 & 203.144 & 12,150 & 5 \\
\hline Yintai & 16 & 540 & 1559 & 110.081 & 1500 & 94 \\
\hline Mutiwan & 17 & 205 & 608 & 42.13362 & 80,500 & 138 \\
\hline Baian & 18 & 1392 & 5073 & 1256.25 & 5890 & 286 \\
\hline Sanchakou & 19 & 614 & 1976 & 50.116 & 180,460 & 100 \\
\hline Xinjian & 20 & 246 & 1047 & 108.808 & 4000 & 12 \\
\hline Shengquan & 21 & 684 & 1950 & 156.11 & 10,000 & 340 \\
\hline
\end{tabular}


The questionnaire survey was primarily selected for the two reasons: (1) it could effectively collect the general information concerning household hollowing status, such as population decline and age rate, out-migration status, visits and roles of out-migrated families, and residents' future concerns; and (2) it could facilitate sample choice in subsequent research that would focus on differences in the hollowing process of rural communities and their influence factors.

\subsection{Modeling Method and Variable Design}

\subsubsection{Logical Framework}

The hollowing process of rural communities is caused by the decline of communitybased autonomy and various activities in conjunction with the decline and aging of their populations. It is characterized not only by land use change but also by the transition of social structure. From the perspective of the rural resilience, a sense of belonging and social participation can mitigate against such decline that is caused by the population declines. Furthermore, the rural resilience emphasizes that compared to the economic function and place-identity, the sense of belonging and primary social contact patterns are subject to much greater inertia [20-22]. Therefore, based on the literature review, this study constructed a logical framework (Figure 2). First, the migration of the young family members produce two results: the aging of the family and the reduction of the family population. Eventually, families become hollowed. As increasingly more families are hollowing, the rural communities change accordingly. On the one hand, due to the population decline and aging, the recreational activities, neighborhood assistance, autonomous participation, and other community factors gradually diminish, resulting in the decline of rural vitality. On the other hand, rural public service provisions are adversely affected, particularly basic public services such as health care and education. The population density of rural areas is lower than the "population threshold" for the operation of the public service system, making the matching of public services difficult and falling into a vicious circle of "high cost, low efficiency, and difficult maintenance," ultimately leading to the reduction of public services. Along with the decline of rural vitality and public service recession, the village begins to be hollowed.

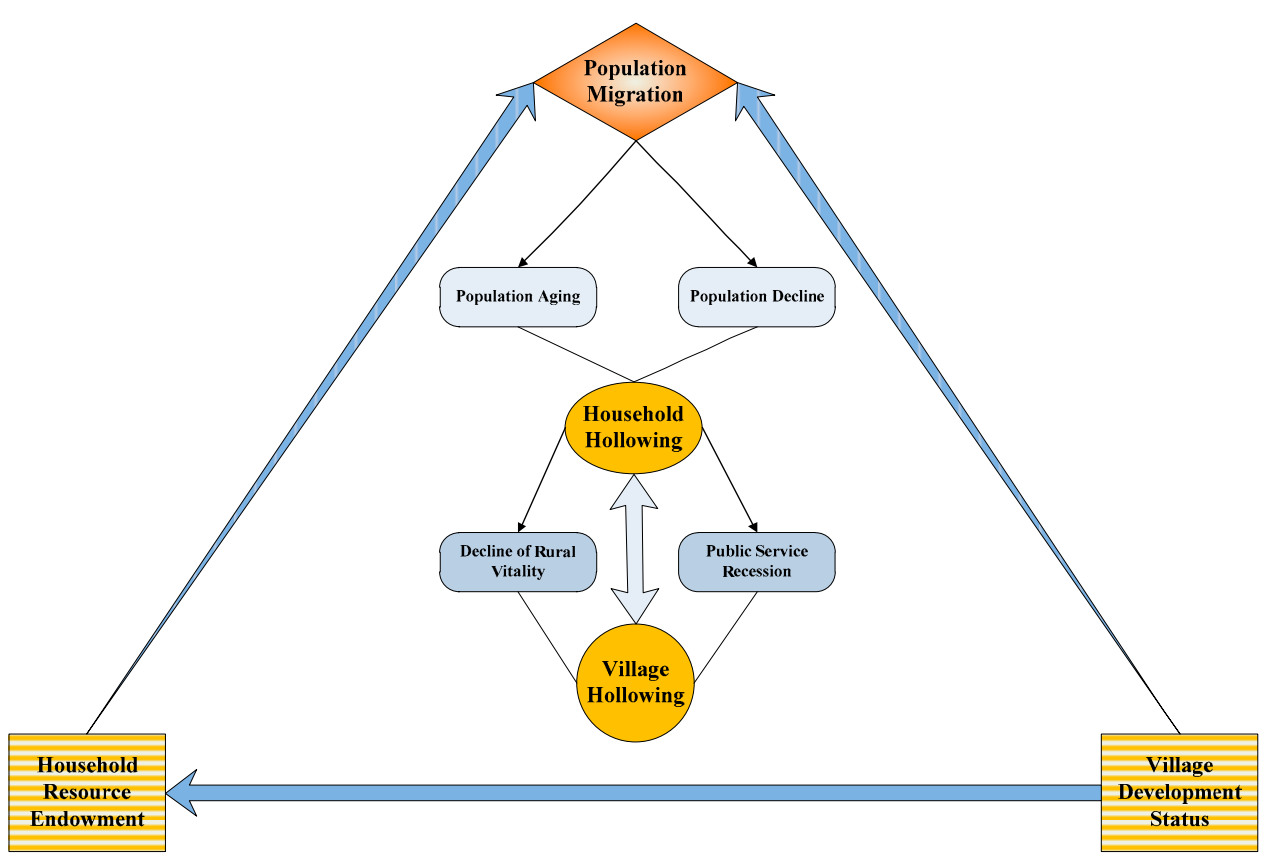

Figure 2. Logical framework of hollowing.

Population migration is the key factor in hollowing and it, together with family resource allocation and rural development conditions, form the influence chain. Household 
resource endowment and village development status affect household hollowing via their influence on population migration. The village development status then influences the household hollowing indirectly through its effect on the household resource endowment. Based on the logical framework of hollowing, this study focused on two aspects, namely the evaluation of household hollowing and the analysis of its influence factors.

\subsubsection{Evaluation System Construction}

Applying a multidisciplinary approach, combining geography, sociology, and demographics, and based on the logical framework, the evaluation index system was established by taking the migration status as the core factor and considering the impact of migration on the size, structure, and vitality of the family. Given the four aspects, the first level in this system considered four indices, that is, (1) population mobility status, (2) family vitality, (3) the link between the out-migrated members and the family, and (4) future concerns of the household.

The first index included two subindices, the rate that people leave home and where these people go. The more people that leave home, the greater the household hollowing. Moreover, the farther people go, the greater the household hollowing. Given the fact that when the younger adults leave, the family vitality decreases. Thus, the age of people staying at home was used to evaluate the family vitality. The closer the link between the outgoing population and the family, the lower the household hollowing degree. To evaluate this link, this study chose two subindices: how often people returned home and how long they stayed. Migration intention reflects the household hollowing trend. The stronger the migration intention, the more likely the occurrence of household hollowing. Overall, there were six subindices, which are listed in Table 2. Through the internet, we consulted 15 experts and researchers to determine the index weight. The group consisted of experts and researchers from the Chinese Academy of Sciences, Yunnan University, Sichuan University, Sichuan Normal University, and Sichuan Agriculture University. Using the analytic hierarchy process (AHP) method, pairwise comparison was used on each indicator to determine its importance.

Table 2. Evaluation index system of household hollowing.

\begin{tabular}{cc}
\hline First Level & Second Level \\
\hline Status of population mobility & $\begin{array}{c}\text { Rate of outgoing people } \\
\text { Where people migrate to } \\
\text { Family vitality }\end{array}$ \\
Age of people staying at home \\
Link between outgoing population and family & How often people return home \\
Household hollowing trend & How long they stay at home \\
\hline
\end{tabular}

\subsubsection{Analysis of Influence Factors}

(1) HLM analysis

Hierarchical linear modeling (HLM) is a complex form of ordinary least squares (OLS) regression that is used to analyze variance in the outcome variables when the predictor variables are at varying hierarchical levels. From the logical framework, the influencing factors were divided into two levels, the household level and the village level, and the hierarchical linear model was then used to explore the influence factors. A hierarchical linear model of the household and village variables was constructed. Households in the same village shared the same variance, given the same situation in the village. The data structure was hierarchical. The model estimated the household levels and implementations when estimating the village-level outcomes.

The procedure is described as follows:

Utilizing HLM 6.08 software, a basic model was established (Model 0). Model 0 conducted a regression on the first and second layers, with no variables in these two layers. 
This model was designed to identify whether the variances came from the difference between villages. The basic form of Model 0 follows:

Level 1 Model: $Y_{i j}=\beta_{0 j}+r_{i j}$

Level 2 Model: $\beta_{0 \mathrm{j}}=\gamma_{00}+\mu_{0 \mathrm{j}}$

If the $p$-value for the final estimation of variance components was significant, it was necessary to establish a variable model at the first level (Model 1). Model 1 conducted a regression on the first layer variables, with no variables in the second layer. This model was designed to determine whether the variances of the intercept and slope ratios of the first level were significant in the second layer. The basic form of Model 1 follows:

Level 1 Model: $Y_{i j}=\beta_{0 j}+\sum \beta_{n j} X_{n i j}+r_{i j}$

Level 2 Model: $\beta_{0 j}=\gamma_{00}++\mu_{0 j}$

$$
\beta_{\mathrm{nj}}=\gamma_{\mathrm{n} 0}+\mu_{\mathrm{nj}}
$$

If the T-test of the variance components was significant, then Model 2, with variables in both the first and second levels, was established. On level 2, the slope(s) and intercept of level 1 become dependent variables that are predicted from the level 2 variables. The basic form of Model 2 follows:

Level 1 Model: $Y_{\mathrm{ij}}=\beta_{0 \mathrm{j}}+\sum \beta_{\mathrm{nj}} X_{\mathrm{nij}}+\mathrm{r}_{\mathrm{ij}}$

Level 2 Model: $\beta_{0 \mathrm{j}}=\gamma_{00}+\sum \gamma_{0 \mathrm{~m}} \mathrm{~W}_{\mathrm{mj}}+\mu_{0 \mathrm{j}}$

$$
\beta_{\mathrm{nj}}=\gamma_{\mathrm{n} 0}+\sum \gamma_{\mathrm{nm}} \mathrm{W}_{\mathrm{mj}}+\mu_{\mathrm{nj}},
$$

where i represents the household; $j$ represents the village; $X$ is the household-level variable; Yij is the household hollowing; $\beta \_0 j$ represents the intercept of group $j ; \beta \_n j$ represents the slope of variable $\mathrm{Xn}$ of group $\mathrm{j} ; \mathrm{r}_{-} \mathrm{ij}$ represents the residual for household $\mathrm{i}$ within group $\mathrm{j} ; \gamma \_00$ and $\gamma \_\mathrm{n} 0$ are intercepts; and $\gamma \_0 \mathrm{~m}$ and $\gamma \_\mathrm{nm}$ represent the slopes predicting $\beta \_0 \mathrm{j}$ and $\beta \_n j$, respectively, from variable $W m$.

(2) Design of the independent variables and hypotheses

\section{(a) Household-level variables and hypotheses}

The literature review and logical framework revealed that out-migration is one of the main reasons for household hollowing [23]. More important types of livelihood capital represent the resource endowments of rural households, and different livelihood capital portfolios can achieve different results, directly affecting whether or not migration occurs [24]. Therefore, in combination with the livelihood capital analysis framework, and fully considering the available data, this study selected six variables involving human capital, social capital, financial capital, and physical capital. A detailed description of the variable design is presented in Table 3 . This study hypothesized that:

(i) Human capital and social capital variables exert positive influences on household hollowing.

(ii) Financial capital and physical capital exert negative influences on household hollowing.

(b) Village-level variables and hypotheses

Family hollowing is subject to the effects of household factors, but it is also affected by village factors. This study focused on the influence of economic development, resource endowment, and interpersonal communication. A detailed description of the variable design is presented in Table 3.

Based on the logical framework, the effects of the village-level variables on household hollowing were divided into two aspects, direct impacts and regulatory impacts. In terms of direct effects, the village factors affect household hollowing via their influence on the household-level factors. For the direct impacts, we hypothesize that: (1) economic development negatively affects household hollowing, that is, the better the economic development, 
the less household hollowing; (2) resource endowment negatively affects household hollowing, that is, the more resource endowment, the less household hollowing; and (3) the interpersonal communication environment positively affects household hollowing. When local elites support villagers leaving home, or when increasingly more people around the inhabitants leave the village, those inhabitants are more likely to choose to leave the village. As a result, household hollowing is high. For the indirect impacts, the village factors affect household hollowing via their influence on the variables of household-level.

Table 3. Variables in the HLM.

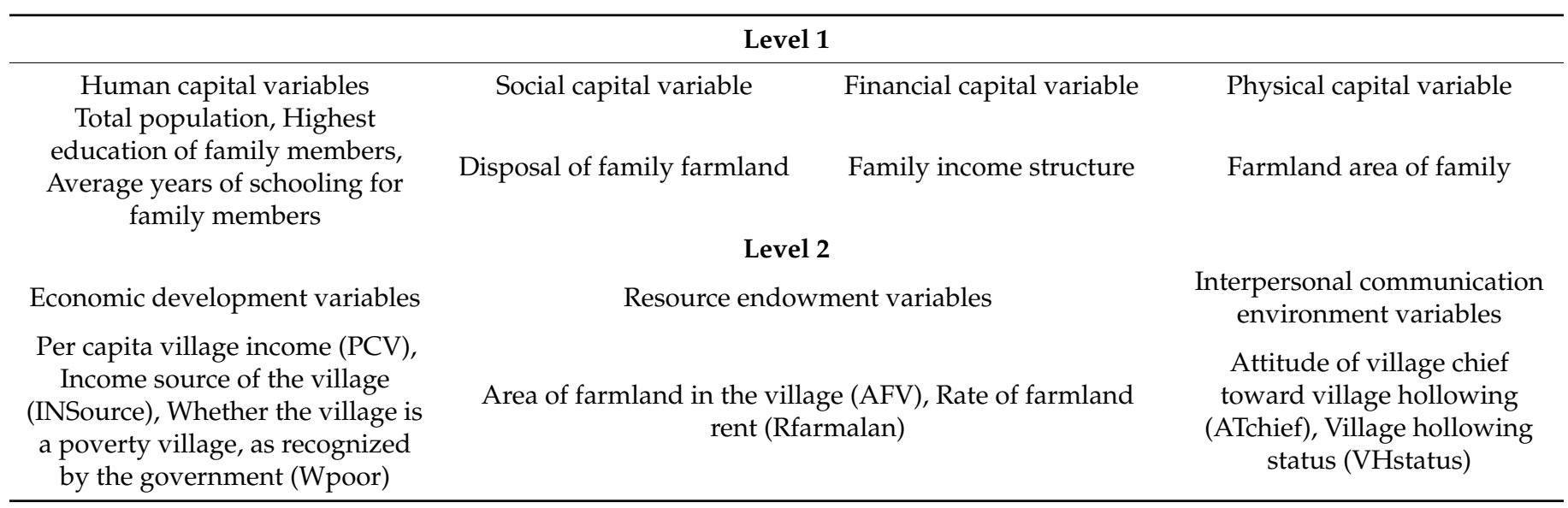

\section{Results}

\subsection{Household Hollowing Characteristics}

\subsubsection{Out-Migration}

There were 499 out-migrations in our investigation, accounting for $25.58 \%$ of the total. Their characteristics are listed in Table 4. The proportion of the population aged 18-30 years was the highest, at $39.88 \%$, followed by those between the ages of 30 and 50 years. There were fewer minors (younger than age 18 years) and elderly (over age 60 years) leaving their villages. The educational background of the out-migrating population was generally low, with $41.68 \%$ having only a junior high school education or less. Those with undergraduate and graduate degrees totaled $8.82 \%$, with only $0.8 \%$ having a master's degree or above. Most people who left tend to return home once or twice a year on average, accounting for $77 \%$ of the total. For $4.85 \%$ of the migrants, their return frequency is not fixed, and can depend on specific circumstances, although not returning home is likely.

Table 4. Migration characteristics (\%).

\begin{tabular}{|c|c|c|c|c|c|}
\hline \multicolumn{2}{|c|}{ Age of Migrant (Years) } & \multicolumn{2}{|c|}{ Education of Migrant } & \multicolumn{2}{|c|}{$\begin{array}{c}\text { Frequency of Returning Home } \\
\text { Per Year }\end{array}$} \\
\hline $0-17$ & 7.82 & & & Variable & 4.85 \\
\hline $18-30$ & 39.88 & No schooling & 6.61 & Once & 54.85 \\
\hline $31-40$ & 17.84 & Junior high school & 41.68 & Twice & 22.15 \\
\hline $41-50$ & 19.24 & Senior high school & 11.02 & 3-5 times & 8.86 \\
\hline $51-60$ & 11.22 & Undergraduate & 8.02 & 6-9 times & 2.95 \\
\hline $61-70$ & 3.01 & Graduate & 0.80 & $\geq 10$ times & 6.33 \\
\hline$>70$ & 1.00 & & & & \\
\hline
\end{tabular}

(1) Migration characteristics of different ages

This study further analyzed the various reasons for leaving home, the different destinations, and the frequency of returning home, among different age groups (Figure 3). In terms of the reasons for leaving, people of different ages can be divided into three groups. The first group consists of the people who were younger than 18 years, most of whom 
migrated for studying. The second group comprises the people aged 30-60 years, who mainly migrated for working. The third group is composed of people older than 60 years, most of whom migrated with their children, in addition to a small number of migrant workers. In general, a plot of the number of people who migrated for work as a function of age tends to resemble an inverted $U$ shape.
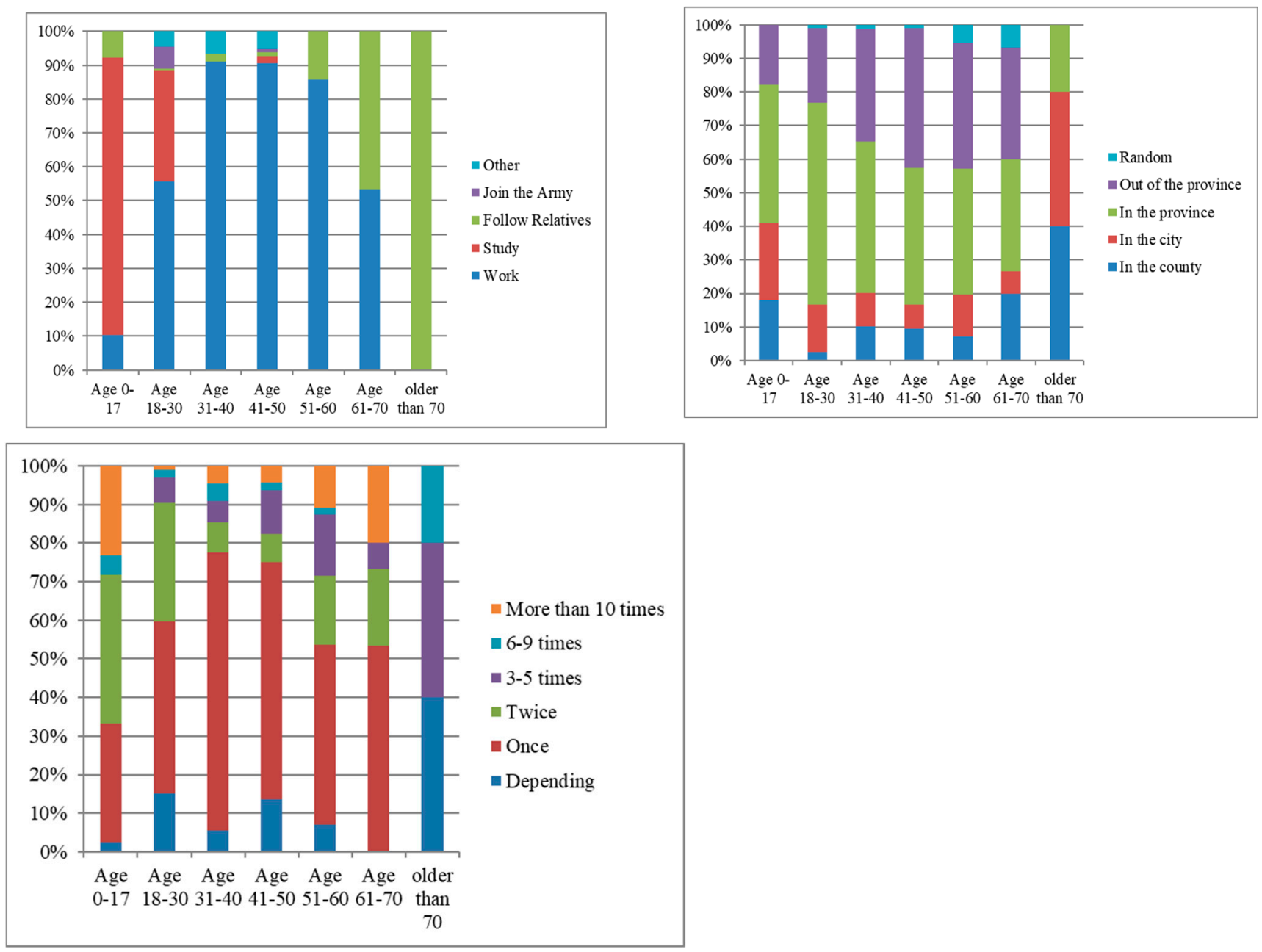

Figure 3. Various reasons for leaving home, migration destinations, and return home frequencies of different age groups.

The migration destination differences among the various age groups are obvious. Most people aged 18-30 years preferred "in the province" as the migration destination, accounting for $60.36 \%$. "In the county" and "in the city" were the main migration destinations for people over 70, accounting for $80 \%$. "In the province" and "out of the province" were both migration destinations for people aged 31-60 years, both exceeding 75\%, while the migration destinations were diverse for people younger than 18 and aged $61-70$ years. For the people younger than $18,41.03 \%$ selected "in the province" as their migration destination, while the other three destinations were relatively evenly distributed. For the people aged 61-70 years, in addition to "in the province" and "out of the province," "in the county" was also a major destination. It is worth noting that people between 51 and 70 were more likely to travel to random destinations, a phenomenon related to job opportunities. These people, especially construction workers, were mainly engaged in labor-intensive work, with unstable jobs, and moved as the job opportunities changed.

The characteristics of the frequency of returning home among the different age groups follow. People aged 31-50 years had the lowest return rate, most preferring to come home only once a year. The frequency of people aged 51-70 years varied, with half returning home once a year and the rest evenly distributed between two or more visits. The group 
aged 18-30 years exhibited the return characteristics of low frequency and high randomness, while the visits of people older than 70 years were both highly frequent and random. People under the age of 18 years exhibited a two-headed trend, with a high proportion going home either 1-2 times or more than 10 times. Generally speaking, the frequency of returning home tended to have an inverted $U$ shape with increasing age.

(2) Migration characteristics of different education levels

The purpose of migrating varied significantly among people with different education levels (Figure 4). As education increased, the proportion of migrations for work decreased and the proportion for study increased. People with a graduate degree or above migrated only for work or study, while other educational groups left for relatively diverse purposes. The lower the level of education, the greater the proportion that followed relatives. The rates of following relatives were $6.98 \%, 4.9 \%$, and $5.15 \%$ for people who not been to school, had a junior high school education, and had a senior high school education, respectively. The people who migrated to join the military were mainly those with high school and undergraduate degrees.
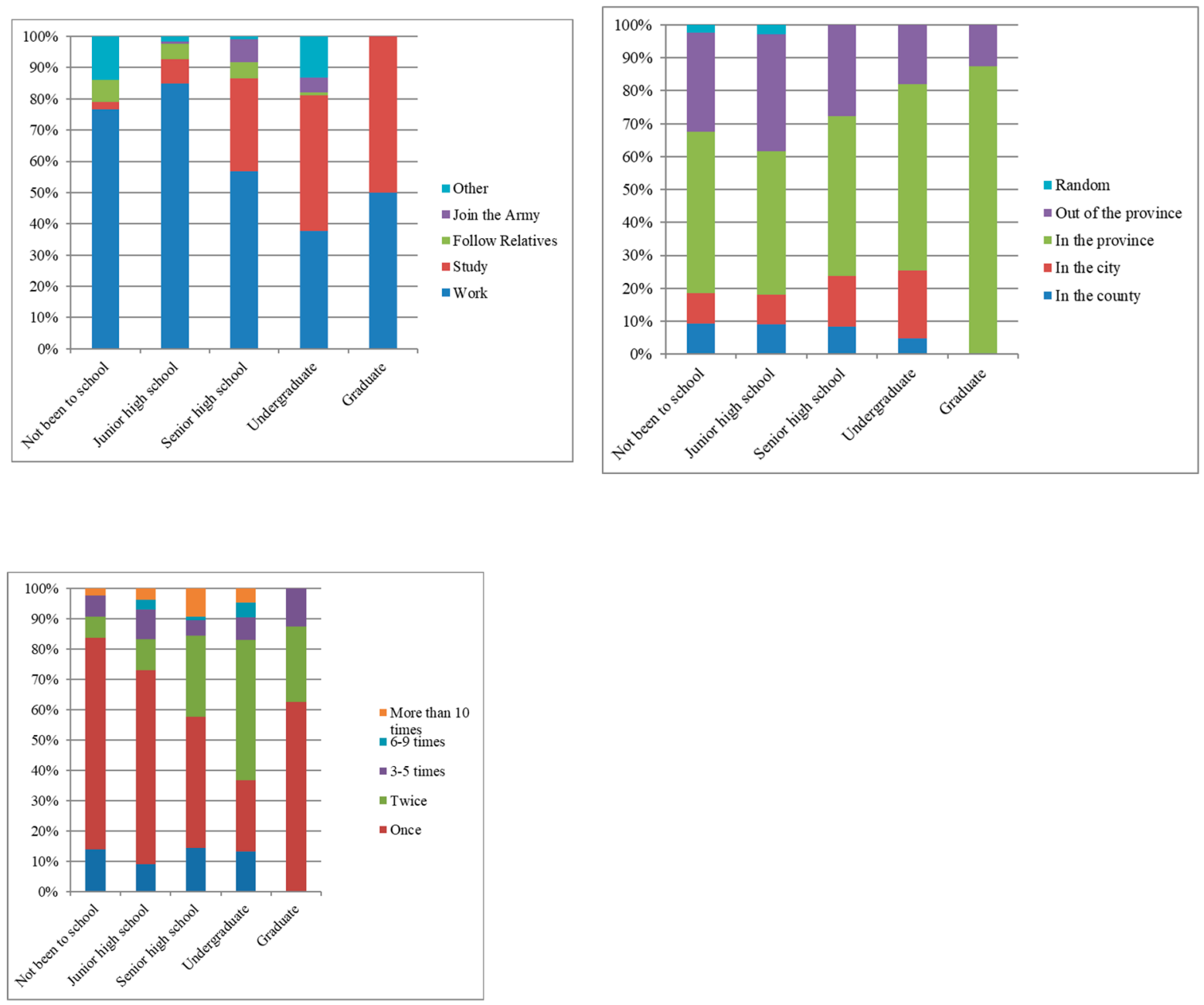

Figure 4. Various reasons for leaving home, migration destinations, and return home frequencies of different education groups.

The migration destination choice was found to be closely related to education level (Figure 4). As the education level increased, the proportion of "in the county" and "out of the province" destinations decreased, while the proportion of "in the province" increased. The main migration destinations of the people with senior high school education or less were "in the province" and "out of the province," while they were "in the city" and "in 
the province" for the people with an undergraduate degree. Most of the people with a graduate degree preferred "in the province" as their migration destination, accounting for $87.5 \%$. The migration destination choice of people with senior high school education or less was slightly random; the proportions of "random" were $2.33 \%$ and $2.86 \%$ for people who had not been to school or had a senior high school education or less.

People with different education levels exhibited varying characteristics in terms of the frequency of returning home. People who had not been to school or with junior high school or undergraduate degrees displayed the characteristics of low frequency and high concentration. Most of them preferred to return home once or twice a year. People with senior high school or undergraduate degrees tended toward highly discrete visits, that is, the proportional distribution of each frequency was similar. They also came home the most often; the people in these groups who returned home more than five times a year were $10.31 \%$ and $9.43 \%$, respectively. With the exception of people with a graduate degree, all other groups exhibited a degree of randomness.

(3) Migration characteristics of different transportation modes

To explore the effects of distance and transportation mode on return home frequency, this study analyzed the relationship between different distances and the modes of transportation with return home frequency. The results revealed that as the distance increased, the return home frequency decreased. When the return travel time was more than five hours, the randomness of returning home was significantly enhanced. In contrast, if the return travel time was only one hour or so, the frequency of going home increased significantly.

The influence of transportation mode on the frequency of returning home was obvious. When the mode was either "by air" or "by car," the randomness of returning home was higher. When the mode of transportation was "by air," most people preferred to go home once or twice a year. When the number of trips home was less than five, the modes of transportation were more diverse, otherwise driving predominated.

\subsubsection{Evaluation of Household Hollowing}

The household hollowing of 26 villages and 453 households was evaluated. For the villages, the maximum value was 5.79 and the minimum value was 2.07 . For the households, the maximum value was 12.17 , while the minimum value was 0.55 .

The median is a better measure of the data since it is not affected by the extremes. The box plot in Figure 5 reveals that the variation of village hollowing was significant. There is one village with a median $<2$, and its box plot is short, that is, its household hollowing value is concentrated.
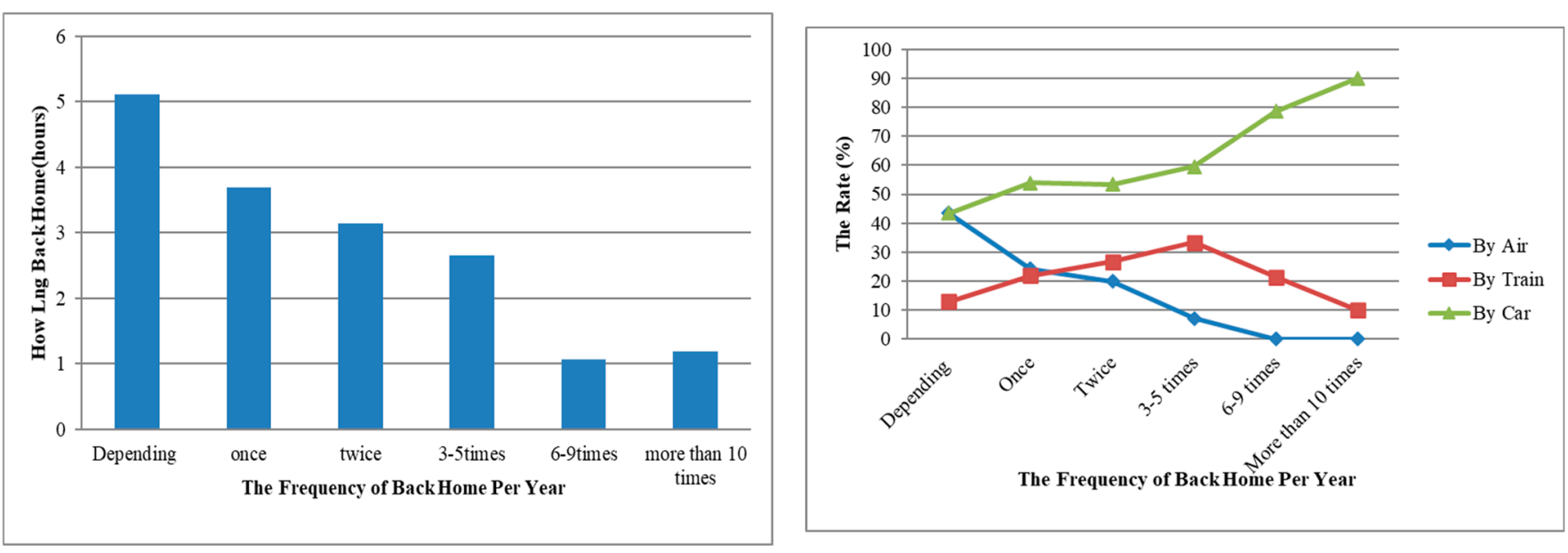

Figure 5. Relationship between the frequency of returning home and the mode of transportation. 
There are 15 villages with median values ranging from 2 to 3 (Figure 6). These villages can be divided into two categories. The first category includes seven villages. The box plots of these villages are short and their medians are roughly in the centers of the boxes, indicating that the household hollowing of these villages is generally low, concentrated, and symmetrical. The second category consists of eight villages. The box plots of these villages are long, that is, the household hollowing variations are significant. Furthermore, the median values of these villages are generally low and the upper quartile and maximum values are generally higher, indicating that the values are more dispersed when the household hollowing value is higher than the median.

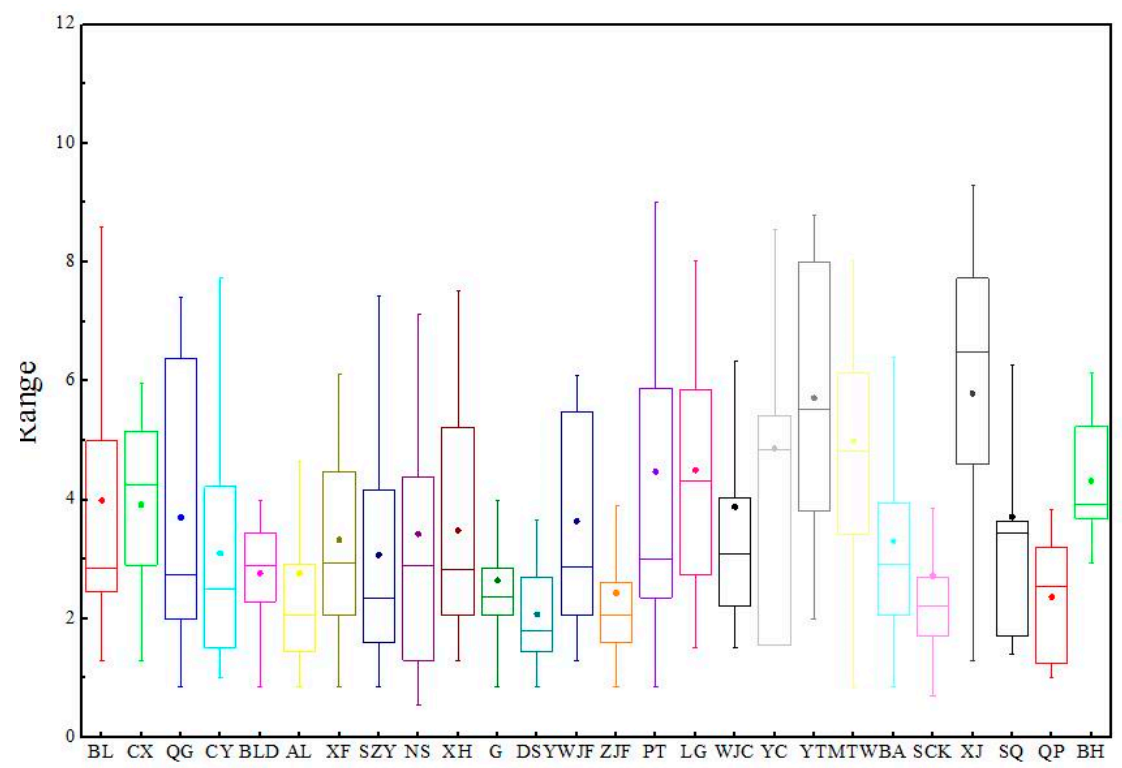

Figure 6. Evaluation of household hollowing.

There are four villages whose median values are between 3 and 4 . Of these villages, two have short box plots and their upper quartile data are approximately 4 , showing that their household hollowing is relatively low. There is one village with a short box plot and a median value close to 4 , demonstrating that its household hollowing is relatively high and concentrated. There is also one village with a long box plot, with a median value that is relatively low and located near the lower quartile; that is, the data distribution is asymmetric and when the value is higher than the median, the household hollowing is dispersed.

There are four villages with median values ranging from 4 to 5 . The household hollowing of these villages is high and its distribution is symmetric. The household hollowing of $Y C$ is particularly high and its median value is close to the upper quartile. The box plots of these villages are of medium length, indicating that their household hollowing differences are relatively significant.

There are two villages whose median values are $>5$. The box plots of these villages are long; that is, the household hollowing of these villages varies significantly. The lower quartile data are greater than 4 , indicating that the household hollowing in these two villages is serious.

\subsection{Influence Factors of Household Hollowing}

\subsubsection{Data and Analysis Characteristics of Model 0}

Based on the research design of the independent variables and the descriptive statistical analysis, Model 0 was established and its results listed in Table 5. The variance components of level 1 and level 2 were 3.771 and 0.779 , respectively. The $\chi 2$-value was 115.17 ( $p=0.001, \mathrm{df}=21$, where $\mathrm{df}$ is the degrees of freedom). This indicated that it was necessary to conduct a two-layer model. Furthermore, by analyzing the variance components 
between these two levels, we determined that the first and second levels accounted for $82.88 \%$ and $17.12 \%$, respectively. This result revealed that the differences between villages led to differences in household hollowing.

Table 5. Final estimation of variance components.

\begin{tabular}{ccccccc}
\hline Random Effect & & $\begin{array}{c}\text { Standard } \\
\text { Deviation }\end{array}$ & $\begin{array}{c}\text { Variance } \\
\text { Component }\end{array}$ & df & Chi-Square & $p$-Value \\
\hline INTRCPT1 & U0 & 0.88236 & 0.77857 & 21 & 115.16792 & 0.000 \\
Level 1 & R & 1.94179 & 3.77053 & & & \\
\hline
\end{tabular}

\subsubsection{Construction of the Optimal Model}

To select the optimal model, we set up three models. In the first model, we added all the variables in level 1 and considered the influence of the level 2 variables on the slope of level 1. The results showed that only Wpoor passed the 95\% significance test (1.863, $p=-0.078)$. In the second model, we deleted the control variables in level 1, leaving only the independent variables. This revealed that Wpoor and INsource passed the 95\% significance test and PCV passed the 90\% significance test. Finally, we constructed Model 3.

\subsubsection{Effects of Household Variables on Family Hollowing}

Among the household variables, three were found to affect household hollowing: highest education of the family, total population of the family, and farmland area of the family (Table 6). The HI_EDU and POP exerted a positive effect on household hollowing, meaning that as the education and population of the family increased, the household hollowing value increased. The influence coefficients of HI_EDU and POP were 0.41 and 0.21 , respectively. Compared to population, education was found to exert a greater impact on household hollowing. This indicates that relative to population quantity, population quality is the key factor affecting hollowing. The FRMAREA was revealed to have a negative effect on household hollowing, with a coefficient of 0.02 . In other words, as the farmland area of the family increased, the household hollowing decreased.

Table 6. Final estimation of fixed effects.

\begin{tabular}{|c|c|c|c|c|c|}
\hline Fixed Effect & Coefficient & Error & T-Ratio & df & $p$-Value \\
\hline \multicolumn{6}{|c|}{ For INTRCPT1, B0 } \\
\hline INTRCPT2, G00 & 1.401765 & 0.265380 & 5.282 & 21 & 0.000 \\
\hline PERCAP, G01 & -0.071 & 0.000040 & -1.759 & 21 & 0.093 \\
\hline WPOOR, G02 & 1.400283 & 0.266209 & 5.260 & 21 & 0.000 \\
\hline INSOURCE, G03 & -0.0575 & 0.000163 & -3.527 & 21 & 0.002 \\
\hline \multicolumn{6}{|c|}{ For HI_EDU slope, B1 } \\
\hline INTRCPT2, G10 & 0.411055 & 0.126049 & 3.261 & 437 & 0.002 \\
\hline \multicolumn{6}{|c|}{ For AV_EDU slope, B2 } \\
\hline \multicolumn{6}{|c|}{ For INCOME slope, B3 } \\
\hline $\begin{array}{c}\text { INTRCPT2, G30 } \\
\text { For POP slope, B4 }\end{array}$ & 0.000423 & 0.001928 & 0.219 & 437 & 0.827 \\
\hline INTRCPT2, G40 & 0.209000 & 0.065596 & 3.186 & 437 & 0.002 \\
\hline \multicolumn{6}{|c|}{ For FRMAREA slope, B5 } \\
\hline INTRCPT2, G50 & -0.02087 & 0.015425 & -0.135 & 437 & 0.096 \\
\hline PERCAP, G51 & -0.001 & 0.000003 & -0.405 & 437 & 0.685 \\
\hline WPOOR, G53 & -0.095385 & 0.030159 & -3.163 & 437 & 0.002 \\
\hline INSOURCE, G54 & 0.0131 & 0.000015 & 8.582 & 437 & 0.000 \\
\hline
\end{tabular}

This study divided the independent and control variables into four categories, comprising human capital, social capital, financial capital, and physical capital variables. The results demonstrated that among the types of livelihood capital, human capital and physical capital influenced household hollowing. This finding is consistent with our hypothesis 
that human capital variables exert a positive influence while physical capital variables exert a negative influence. Resource endowments made little difference, however, with a coefficient of only 0.02 .

\subsubsection{Effects of Village Variables on Family Hollowing}

The effects of village variables on household hollowing include two aspects: direct effect and regulatory influence. First, there are three village variables that affect household hollowing directly, including per capita of the village (PCV), whether the village is a poverty village, as recognized by the government (WPOOR), and the income source of the village (INSOURCE). PCV and INSOURCE were both found to exert a negative effect on household hollowing. The coefficient of the per capita effect was 0.071; when it was lower, the household hollowing was higher. In this study, the value of the income source represents the diversification of income, that is, the greater the value, the greater the income diversity. The negative effect indicates that as the income diversity increased, the household hollowing decreased. WPOOR was found to exert a positive effect on household hollowing. This shows that the household hollowing of the villages that are not recognized by the government as poverty villages was more serious.

Second, WPOOR and INSOURCE influenced household hollowing indirectly via their effects on the slope of FRMAREA-Yij. WPOOR weakened the positive influence farmland area had on household hollowing. Due to the effect of WPOOR, the coefficient of FRMAREA decreased by 0.09. In the villages that are not recognized by the government as poverty villages, the connection between farmland area and household hollowing was much weaker. In other words, the influence of farmland area on household hollowing is less important in a village with higher economic development. INSOURCE strengthened the positive influence of farmland area on household hollowing. Due to the effect of income source, the coefficient of farmland area increased by 0.013 . This result indicates that, in the villages with diversified income sources, the connection between farmland area and household hollowing is much stronger.

\section{Discussion}

The household-level variable was determined to be endogenous drive, while the community-level variables consisted of exogenous drive, endogenous influence factors leading to rural hollowing, and exogenous influence factors accelerating it.

The conclusion that the influence of WPOOR is contrary to the effect of PCV reveals the influence of endogenous and exogenous variables on hollowing. The effect of PCV indicates that the worse the economy, the worse the rural hollowing. Todaro emphasized that the effect of economic factors was the key to explaining rural-urban migration [25]. In the regions with the slow economic development and fewer job opportunities available, people have to migrate. As a result, rural hollowing in these regions was worse. It is worth noting that the influence of WPOOR, however, shows that the rural hollowing of the villages recognized by the government as poor villages is better. In reality, the economic development of these villages was lowest. The rural hollowing in these regions, however, was not the worst. Through our analysis, the overall population quality of nonpoor villages is higher than that of poor villages. The average length of schooling for poor villages is 4.48 years, while it is 7.56 years for nonpoor villages. Education is one of the cores of human capital. That is, the villages that were recognized by the government as poor villages have lower levels of human capital. According to the human capital theory, human capital is a determining factor for migration [25]. Liu et al. reported that education was the most influential factor, and once education levels exceeded junior college and education level increased, the ratio of residential willingness increased [26]. Furthermore, the impact of human capital-social capital matching on the migration is significant [27]. The human capital of poor villages is at a low level, so its social capital structure is single and the degree of homogeneity is high, which has a restraining effect on migration; thus, the population is in a state of "want to migrate but cannot." Considering all of these characteristics, the 
relationship between the PVC and WPOOR indicated that endogenous drive was more important than exogenous drive for rural hollowing. Our conclusion also supports these findings. Because endogenous variables play a decisive role in rural hollowing, even with better economic development, the rural hollowing of nonpoor villages is more serious. On the one hand, when endogenous variables are relatively consistent, we can compare exogenous variables. For example, since the population quality differences in the nonpoor villages are not significant, we could compare the economic development of these villages. This comparison revealed that the worse the economic development, the more serious the rural hollowing. On the other hand, when there are large differences in endogenous variables, the endogenous variables play a decisive role, a relationship that is supported by the situations of poor villages.

Considering all the above, in addition to the individual characteristics, the rural environment also affects rural hollowing. More importantly, from the perspective of rural hollowing, the relationship between population hollowing and rural sustainable development is complex. For some villages, population hollowing is a serious problem. The loss of talent accelerate rural hollowing and hinder rural sustainability. Meanwhile, for other villages, rural hollowing is not a serious problem. One reason for this is the low quality of their populations, and population quality is the key factor for rural sustainability. Thus, a high amount of hollowing cannot be simply classified as unsustainable and a low amount as sustainable. Instead, the causes of the hollowing differences should be comprehensively analyzed.

The loss of highly educated talent aggravate the trend of rural hollowing and hinder the sustainable development of the countryside.

The impact of human resources is mainly and most importantly at the family level, with population quantity and quality being the key factors. The richer the human resources of the family, the more serious the household hollowing. Moreover, compared with population quantity, population quality is more important. The coefficient of HI_EDU effect was 0.4 , while it was 0.2 for POP. This influence is reflected in two aspects. First, social integration is one of the key factors affecting the intention to migrate. According to the literature, as the education level increases, the ratio of migration intention increases [26]. With higher education, migrants have opportunities to obtain higher income and welfare, helping them to integrate into cities. More important, the return intention of people with high level education was lower [26]. As a result, it becomes more likely that they guide their entire family to migrate. This is consistent with our findings. When the highest level of education of a family was a bachelor's degree or above, $31.01 \%$ of families thought it was very likely that they would leave the village in the future. It has been reported that the higher the highest degree of a family member, the stronger the willingness of the family to migrate. For the villages with more family migration, the social network of these villages was better. Social capital theory emphasizes the important role of social network in the process of migration. The accumulation of social capital in the destination increases the opportunity of migration, the social network of the sending region is a kind of push on migration [28]. More important, when the level of human capital is high, the heterogeneous resources in the social capital of rural-urban floating population increase, and the top resources reached through the social network are more, which has a decisive positively impact on the migration decision. As a result, the loss of highly educated talent may drive more migration [27]. Second, residents often receive a variety of support from out-migrated family members who live close to the community. Once this type of support exists and expands to community-based activities, the community functions may not decline as rapidly as shown in the framework [1]. Since prefecture-level cities lack the ability to attract talent, our findings revealed that the frequency of returning home of highly educated family members is low and they often prefer cities as their migration destination. This shows that highly educated family members have less access to and care for their families. This study found that for household hollowing, the family elite exert a significant driving effect. In addition, household hollowing is directly related to rural hollowing. As 
a result, a key to reducing rural hollowing and promoting sustainable development is to guide the return of talent and establish policies to attract highly educated talent.

In addition to promoting economic development and its diversification to alleviate rural hollowing, improving the quality of the population is more important in the countryside.

Sustainable villages feature attributes that include a moderate-sized population, sound economy, and vibrant rural function [1]. Population is the root, economy is the fertilizer, and function is the fruit. From our research results, in addition to retaining people, improving the quality of the population is more important for alleviating hollowing. First, due to the migration of heterogeneous labor force, talent in backward areas is more scarce [29]. Based on the literature, rural residents who continue to study after graduating from junior high school will reduce the possibility of rural residents to migrate across counties and cities. However, families cannot support scholars, so they often choose to migrate [30]. Thus, targeted improvement of regional education level is conducive to inhibiting population migration, thus slowing down the degree of hollowing out and promoting regional sustainable development. Second, our findings revealed that the household hollowing of the villages that are not recognized by the government as poverty villages is more serious. This result is contrary to the conclusion that rural economic development and rural hollowing are negatively correlated. In our investigation, among the 26 villages, three are recognized by the government as poverty villages. In $60 \%$ of the families in these three villages, the highest education level is primary school, and in $15 \%$ of the families, all members are illiterate. There are no people with undergraduate degrees in these three poverty villages. In contrast, the highest educational level of the families is more evenly distributed in the remaining villages. All members are illiterate in only $7 \%$ of the families, while in $2 \%$ of the families, the highest educational achievement is undergraduate or above. Population quality hinders migration in the government-recognized poverty villages, so although the economic development of these villages is not good, the degree of rural hollowing is lower [31]. Although the rural hollowing is not serious, it is not sustaining villages, because the root is not healthy, and cannot bear nutritional fruit. Generally, the greater the improvement in population education level, the stronger the promotion effect on the regional economic growth [29]. This is especially true for the villages that are recognized as poor villages by the government. Thus, improving the quality of the population is more important in the countryside.

Of course, in addition to population, economic development as the fertilizer is also very important. Michael P. Todaro emphasized that the effect of economic factors was the key to explaining rural-urban migration [25]. Our results support this view, using per capita net income to measure rural economic development, and demonstrated that as the per capita net income increased, the household hollowing decreased. To put it another way, people migrate from rural to urban areas in search of higher incomes. From the point of view of push-pull theory, there are urban pull forces and rural push forces, namely the higher income of urban areas and the lower economic development of rural areas. When the rural economy develops well, the thrust of migration will be weakened. Furthermore, according to our study, the higher the diversity of family income, the lower the household hollowing. When households derive part of their income from tourism, the amount of hollowing is low. Therefore, promoting the diversified development of the rural economy, particularly the development of rural tourism, is helpful for alleviating hollowing.

\section{Conclusions}

This study examined the process of population hollowing and to determine the factors that affect rural hollowing in order to establish the key to sustainable development in rural areas. To explore the process of population hollowing, migrant characteristics, including the purpose of migration, migration destination, and frequency of returning home, were analyzed. An HLM model was then constructed to find the factors considering the family level and regional level. The results led to the following conclusions: 
(1) The difference of rural hollowing in different villages was significant. According to the median values, the villages were divided into four categories. Furthermore, considering the shape of the box diagram, it can be further subdivided into eight subcategories. The subcategories represent the difference of family hollowing in different villages.

(2) The difference of migration characteristics among people with different ages and education levels was obvious. The distribution with age of people migrating for work and the frequency of returning home both tended to exhibit an inverted $U$ shape. As education increased, the proportion of migration for work decreased. For the frequency of returning home, with the exception of people with a graduate degree, all others exhibited a degree of randomness.

(3) Through the relationship between the family level and regional level, the differences between villages led to differences in household hollowing. The analysis of the variance components between these two levels showed that the first and second levels accounted for $82.88 \%$ and $17.12 \%$, respectively. From perspective of the family level, there were three factors that affected household hollowing: highest education of the family, total population of the family, and farmland area of the family. Among the three factors, the influence of highest education of the family was the most significant, indicating that human capital was most important during the process of rural hollowing. From perspective of the regional level, two features are important: first, there are three village variables that affect household hollowing directly-per capita of the village (PCV); whether the village is a poverty village, as recognized by the government (WPOOR); and the income source of the village (INSOURCE). Both PCV and INSOURCE were found to exert a negative effect on household hollowing. Second, the variables WPOOR and INSOURCE influenced household hollowing indirectly via their effects on the slope of FRMAREA-Yij.

This study analyzed the hollowing process in China. Generally, urbanization and industrialization have been considered the main factors affecting population hollowing. In the process of urbanization, Japan is faced with the same problem of rural hollowing. By 2030, the global urbanization rate is projected to reach about $60 \%$, with most of the growth coming from developing countries, leading to an increasing amount rural outmigration in developing countries. Therefore, the hollowing process of China and Japan can provide certain reference for developing countries in Asia that are currently accelerating urbanization, such as Vietnam, which is currently experiencing a period of accelerated migration from rural to urban areas.

Author Contributions: Conceptualization, Y.L.; methodology, Y.L. and L.P.; software, Y.L.; formal analysis, Y.L.; investigation, L.S.; data curation, L.S.; writing—original draft preparation, Y.L.; writing-review and editing, L.P.; visualization, Y.L. and L.S.; funding acquisition, Y.L. and L.P. All authors have read and agreed to the published version of the manuscript.

Funding: This research was funded by the National Natural Science Foundation of China (Grant Nos. 41801140, 41930651, and 41771194).

Data Availability Statement: The statistics used in this study originated from the survey data of the field investigation that took place during January 2020 in Sichuan Province, China.

Acknowledgments: Any opinions, findings, conclusions, or recommendations expressed in this material are those of the authors and do not necessarily reflect the views of the sponsoring parties mentioned above.

Conflicts of Interest: The authors declare no conflict of interest.

\section{References}

1. Kudo, S. Divergence of the sustaining and marginalizing communities in the process of rural aging: A case study of Yurihonjo-shi, Akita, Japan. Sustain. Sci. 2013, 8, 491-513. [CrossRef] 
2. Pei, H.; Chang, C.; He, W.; Shen, Y.; Shen, Y. Depopulation of rural areas under the backdrop of urbanization-A case study of Kangbao County, Northwest of Hebei Province. Chin. J. Eco Agric. 2009, 1, 169-173. [CrossRef]

3. Jiang, S.; Luo, P. A literature review on hollow villages in China. China Popul. Resour. Environ. 2014, 24, 51-58.

4. Long, H.; Li, Y.; Liu, Y. Analysis of evolutive characteristics and their driving mechanism of hollowing villages in China. Acta Geogr. Sin. 2009, 1203-1213.

5. Yang, R.; Liu, Y.; Chen, Y. Comprehensive measure and partition of rural hollowing in China. Geogr. Res. 2012, 31, 1697-1706.

6. Mcleman, R.A. Settlement abandonment in the context of global environmental change. Glob. Environ. Chang. 2011, 21, S108-S120. [CrossRef]

7. Mcleman, R.A.; Hunter, L.M. Migration in the context of vulnerability and adaptation to climate change: Insights from analogues. Wiley Interdiscip. Rev. Clim. Chang. 2010, 1, 450-461. [CrossRef] [PubMed]

8. Berrang-Ford, L.; Ford, J.D.; Paterson, J. Are we adapting to climate change? Glob. Environ. Chang. 2011, 21, 25-33. [CrossRef]

9. Buckley, B.M.; Anchukaitis, K.J.; Penny, D.; Fletcher, R.; Cook, E.R.; Sano, M.; Le, C.N.; Wichienkeeo, A.; Minh, T.T.; Hong, T.M. Climate as a contributing factor in the demise of Angkor, Cambodia. Proc. Natl. Acad. Sci. USA 2010, 107, 6748. [CrossRef]

10. Warner, K.; Ehrhart, C.; Sherbinin, A.D.; Adamo, S.; Chaionn, T. Search of Shelter: Mapping the Effects of Climate Change on Human Migration and Displacement; UN High Commissioner for Refugees: Geneva, Switzerland, 2009; pp. 493-502.

11. Calderón, G.; Macías, J.M.; Serrat, C.; Villegas, C. At Risk: Natural Hazards, People's Vulnerability and Disasters; Routledge: London, UK, 1996.

12. Crighton, E.J.; Elliott, S.J.; Meer, J.V.D.; Small, I.; Upshur, R. Impacts of an environmental disaster on psychosocial health and well-being in Karakalpakstan. Soc. Sci. Med. 2003, 56, 551-567. [CrossRef]

13. International Organization for Migration. Climate Change, Migration and Critical International Security Considerations; IOM: Belgrade, Serbia, 2012.

14. Mitchell, C.J.A. Counter urbanization and the Growth of Canada's Rural and Small Town. J. Rural Stud. 2008.

15. De Matteis, G. Urbanization and Counter-Urbanization. Ekistics Rev. Probl. Sci. Hum. Settl. 1986, 53, $26-33$.

16. Tian, Y.; Han, D. Urbanization and the end of village. Jilin Univ. J. Soc. Sci. Ed. 2011, 11-17.

17. Li, Y.; Wang, H. Spatial distribution of rural population flow at the village level in China: Evidence from village samples in the third national agricultural census. Chin. Rural Econ. 2020, 124-144.

18. Liu, Y.; Liu, Y.; Zhai, R. Geographical research and optimizing practice of rural hollowing in China. Acta Geogr. Sin. 2009, 1193-1202.

19. Liu, Y.; Liu, Y. Progress and prospect on the study of rural hollowing in China. Geogr. Res. 2010, $29,35-42$.

20. McManus, P.; Walmsley, J.; Argent, N.; Baum, S.; Bourke, L.; Martin, J.; Pritchard, B.; Sorensen, T. Rural Community and Rural Resilience: What is important to farmers in keeping their country towns alive? J. Rural Stud. 2012, 28, 20-29. [CrossRef]

21. Schwarz, A.M.; Bene, C.; Bennett, G.; Boso, D.; Hilly, Z.; Paul, C.; Posala, R.; Sibiti, S.; Anfrew, N. Vulnerability and resilience of remote rural communities to shocks and global changes: Empirical analysis from Solomon Islands. Glob. Environ. Chang. 2011, 21, 1128-1140. [CrossRef]

22. Beekman, G.; Heide Heijman, W.; Schouten, M. Social capital and resilience in rural areas: Responses to change. Mansholt Grad. Sch. Soc. Sci. 2009, 46, 6418-6436.

23. Liu, Y.; Yu, L.; Chen, Y.; Long, H. The process and driving forces of rural hollowing in China under rapid urbanization. J. Geogr. Sci. 2010, 20, 876-888. [CrossRef]

24. Wan, J.; Deng, W.; Song, X.; Liu, Y.; Zhang, S.; Yi, S.U.; Yafeng, L.U. Spatio-Temporal Impact of Rural Livelihood Capital on Labor Migration in Panxi, Southwestern Mountainous Region of China. China Geogr. Sci. 2018, 28, 153-166. [CrossRef]

25. Lindstrom, D.P. Economic opportunity in mexico and return migration from the United States. Demography 1996, 33, 357-374. [CrossRef] [PubMed]

26. Liu, Y.; Deng, W.; Song, X. Influence factor analysis of migrants $\backslash$ " settlement intention: Considering the characteristic of city. Appl. Geogr. 2018, 96, 130-140. [CrossRef]

27. Han, S. Research on the Impact of Human Capital and Social Capital Matching on the Migration Behavior and Career Choice of Rural-Urban Migrants. Ph.D. Thesis, Northwest AF University, Xianyang, China, 2020.

28. Constant, A.; Massey, D.S. Return Migration by German Guestworkers: Neoclassical versus New Economic Theories. Int. Migr. 2002, 40, 5-38. [CrossRef]

29. Duan, Z.P. An analysis of the impact of the educational level difference of the interprovincial migration population on economic growth and regional disparities in China. J. China Univ. Geosci. 2013, 115-121.

30. Ye, H. Education and Migration: College admission and cross-county Mobility of rural registered population. Jianghai J. 2016, 3, 111-119.

31. Childs, G.; Craig, S.; Beall, C.M.; Basnyat, B. Depopulating the Himalayan Highlands: Education and Outmigration from Ethnically Tibetan Communities of Nepal. Mt. Res. Dev. 2001, 34, 85-94. [CrossRef] 